\title{
A educação popular às voltas com a Sociedade da Informação: potencialidades, riscos e particularidades
}

\author{
Nathalie Boucher-Petrovic ${ }^{*}$
}

\begin{abstract}
Resumo Como explicar que atores da educação popular se refiram a uma sociedade chamada "da informação", parecendo assim inserir-se nesse projeto de intenção federativa que é hoje promovido pelos empresários e pelo poder público? Resultante de uma história longa e plural, a educação popular não constitui um todo homogêneo. Mas sua marca é uma filosofia comum que trabalha para a emancipação social, cultural e política do povo. De fato, a referência à sociedade da informação seria o meio de reatualizar as problemáticas que interessam aos atores da educação popular, além de superar a crise de sentido que eles enfrentam. Enfim, se essa aproximação parece, à primeira vista, favorecer o consenso, os conflitos inerentes ao confronto de valores e identidades continuam vivos e revelam os verdadeiros desafios que tal encontro promete.
\end{abstract}

Palavras-chave educação popular, sociedade da informação, ideologia, utopia, espaço público.

\begin{abstract}
How can we explain that some Popular education militants are also referring to the Information Society and thus seem to join this plan, carried to a great extent by merchants and the authorities? Popular education, in addition to a long and plural history, is not homogeneous. However, Popular education is marked by a common philosophy aiming at developing social, cultural and political people's emancipation. Indeed, the reference to the Information Society allows the militants of Popular Education to update their traditional issues, and also to overcome the crisis they are facing. Lastly, if this meeting seems, at first sight, to generate consensus, the inherent conflicts in the confrontation of the values and identities do not therefore disappear and question the real stakes at work.
\end{abstract}

Keywords popular education, information society, ideology, utopia, public spaces.

\section{Introdução}

Quando se trata de renovar a discussão sobre a difusão generalizada das redes informáticas e das tecnologias de informação e de comunicação (TIC) e, assim, de analisar o que está contido no conceito de sociedade da informação, parece que a relação entre os movimentos de educação

\footnotetext{
* Nathalie Boucher-Petrovic é doutoranda em Ciências da Informação e da Comunicação, Universidade Paris 13 (Labsic) e Maison des Sciences de l'Homme Paris Nord. Com o apoio do INJEP (Institut National de la Jeunesse et de l'Éducation Populaire).

** Tradução de Estela dos Santos Abreu.
} 
popular e esta sociedade abre interessantes pistas de reflexão. Estes movimentos, marcados por origens históricas ricas e plurais mas que hoje buscam uma identidade, permitem esmiuçar as problemáticas ligadas aos TIC em nossa sociedade. A educação popular, como campo de práticas atuando no âmago do social, reinterroga de modo inédito os objetivos socioculturais da informatização social. Por sua inserção histórica e social, esses movimentos, ainda pouco estudados sob o aspecto sociológico e comunicacional, ajudam a esclarecer a passagem da informatização da sociedade à sociedade da informação, bem como as mutações sociopolíticas que se manifestam atualmente. Permitem também destacar as diferentes ligações com valores subjacentes à idéia de uma sociedade da informação, que os movimentos de educação popular assimilam de modo diferenciado.

\section{Educação popular e sociedade da informação: um encontro improvável?}

Nesta primeira parte, examinaremos em que aspectos a referência à sociedade da informação pelos atores da educação popular não é de fato acidental; ela se insere numa certa continuidade. Também veremos certos elementos conjunturais que parecem determinantes para a concretização desse encontro. Tais análises ajudam a apreender o meio da educação popular e suas atuais evoluções.

\section{Educação popular: um campo ${ }^{1}$ complexo e um desafio de poder}

Apreender a educação popular, comprender o que esse termo contém, sua evolução histórica e seu atual status na sociedade francesa não é fácil, pela grande complexidade que a envolve. As inúmeras definições que tentam caracterizá-la mostram que a própria definição do campo constitui um desafio que vai bem além do quadro discursivo e é próximo do nível político. Tratase de um conjunto de definições que vão da descrição do processo de educação popular até a das finalidades, que quase sempre reafirmam os valores fundadores desse movimento pelo apelo à história.

\section{Uma esclarecedora herança histórica}

Criado no século XIX, o conceito de educação popular expressa uma tendência e ideais que são anteriores ao surgimento do termo. Por exemplo, o relatório de Condorcet sobre a Organização Geral da Instrução Pública, ${ }^{2}$ que, para muitos militantes, assinala o ponto de partida e de adesão a esse movimento, é do fim do século XVIII (1792). Nesse relatório, Condorcet afirma a

\footnotetext{
${ }^{1}$ Tomamos aqui como base as propriedades de campos segundo Bourdieu (1992). A utilização dessa noção permite caracterizar nosso objeto que, sob vários aspectos, lhe é bem próximo, mas mesmo essa noção será questionada no decorrer deste artigo.

${ }^{2}$ Relatório apresentado à Assembléia Legislativa em 20 e 21 de abril de 1792.
} 
necessidade de instaurar uma instrução para todos e para todas as idades. De fato, a educação popular na sua vertente tradicional fundamenta-se no ideário humanista herdado do Iluminismo, que procurava esclarecer o povo proporcionando-lhe o saber. No século XIX, durante o qual surgem as classes operárias produto da industrialização, desenvolveram-se cursos para adultos, associações e bibliotecas populares, bolsas de trabalho, universidades para o povo, sociedades de socorros mútuos, cooperativas, e também grandes associações (antes da lei sobre o contrato de associação de 1901) como a Liga do Ensino (1866). Foi então que se começou a falar em educação popular. Na sua evolução, a educação popular passou por altos e baixos da história social, com muitas consequiências para a orientação do movimento. Reciprocamente, ela participou de muitas evoluções, como a da implantação do ensino leigo, gratuito e obrigatório. Não cabe aqui retraçar essas evoluções, mas convém assinalar a diversidade de correntes que formam a educação popular, a fim de explicar, ao menos em parte, a heterogeneidade que a caracteriza. Historicamente, a educação popular foi obra dos leigos republicanos, dos católicos (catolicismo social) e dos protestantes. No século XX, a educação popular foi revigorada no período do Front Populaire (1936), pela ampliação do tempo livre e do lazer, por inúmeros movimentos surgidos da resistência e, depois, da libertação. Esse período marcou o início do processo de institucionalização da educação popular: em 1945, Jean Guéhenno foi nomeado para a Direção da Educação Popular, "a primeira verdadeira organização oficial da educação popular" (CACÉRÈS, 1964, p. 151). A institucionalização foi feita a seguir por meio do sistema de credenciamento e pela instalação sob tutela ministerial; enfim, a partir dos anos 1960, todo um setor da educação popular se confundiu com a animação sociocultural, com a educação permanente, ${ }^{3}$ com as políticas de inserção etc. Assim, de uma origem baseada na militância e no trabalho voluntário, os movimentos e os atores da educação popular foram aos poucos se profissionalizando e foram integrados a dispositivos públicos. Para muitos observadores, essa evolução marcou o declínio da educação popular: instrumentalização, profissionalização, especialização, funcionalização (CARTON, 1995). Veremos mais adiante que daí surgiu, de uns anos para cá, a vontade por parte dos atores de rever esse movimento que atravessa uma crise de significado.

Este breve resumo histórico talvez ajude a comprender os quadros histórico, social e ideológico que condicionam as representações que os atores da educação popular elaboram em relação ao movimento que defendem. A educação popular se define, segundo os casos, com referência a:

- finalidades tais como a emancipação (social, cultural e política) do povo, a formação crítica dos cidadãos, o engajamento individual e a apreensão das problemáticas de nossas sociedades a fim de agir de acordo com elas; ${ }^{4}$

- um trabalho da cultura na transformação social (LEPAGE, 2001, p. 1), um trabalho que consiste em interrogar as representações (LEPAGE, 2001, p. 40), um trabalho rigoroso de transformação da experiência cotidiana do mundo popular em saber estratégico e em ação coletiva, isto é, em trabalho de engajamento cívico (CARTON, 1998b);

- a dimensão cultural da produção da ação coletiva (CARTON, 1995, p. 6), um direito à inteligência política (DOUARD, 2000), um processo de conscientização (FREIRE, 1974), uma ideologia, uma prática social, um campo de práticas, um estado de espírito militante (POUJOL, 1995).

\footnotetext{
${ }^{3}$ Lei de 16 de julho de 1971 referente à organização da formação profissional contínua no âmbito da educação permanente.

${ }^{4}$ Fédération Française des Maisons des Jeunes et de la Culture, apresentação no site da internet de Coordination Sud: www.coordinationsud.org/coordsud/membres/ffmjc.html\#princ (página consultada em 25 de março de 2004).
} 


\section{Uma realidade muito heterogênea}

Existem cerca de 880.000 associações $^{5}$ declaradas na França e 60.000 novas associações por ano, o que atesta um certo dinamismo. Entre essas associações, 432 trazem o selo de credenciamento da Jeunesse et Éducation Populaire [Juventude e Educação Popular] ${ }^{6}$ (em âmbito nacional), e várias outras associações dispõem da aceitação local. Nesse conjunto heterogêneo, encontram-se ao mesmo tempo federações históricas (La Ligue de l'enseignement, Léo Lagrange, Peuple et Culture etc.) [A Liga do Ensino, Léo Lagrange, Povo e Cultura etc.] e pequenas associações de âmbito local atuando numa área ou domínio bem específico. Segundo Poujol, a educação popular situa-se no espaço social que não é ocupado pelas igrejas, pelos sindicatos, pela escola, pelas empresas (POUJOL, 1980, p. 108) e procura ser um complemento do sistema escolar.

No entanto, não é fácil definir a educação popular, por causa das diferentes heranças que ela invoca, das evoluções ou transformações que sofreu, e até dos conflitos internos entre grandes federações e jovens associações que a ela se referem (ex.: ATTAC), ou ainda dos novos movimentos que a ela não se referem explicitamente mas cujo projeto é bastante parecido. Por isso, a educação popular parece renascer através de múltiplos projetos cada vez mais diversificados, o que para alguns é sinal de uma nova atualidade. O encontro entre educação popular e sociedade da informação, que analisamos neste trabalho, é uma das manifestações dessa atualidade.

Por toda a parte, sob denominações diversas, surgem novos projetos de educação popular: cidade educadora, casas do saber e da cidadania, universidade de todos os saberes [...] Esse despontar não é fortuito. Se a "velha" utopia da educação popular conhece uma nova atualidade é porque responde às mais modernas preocupações [...] (RICHEZ, 2000, p. 2).

De fato, bem ancorada no tecido associativo, a educação popular não se reduz, porém, ao mero meio associativo nem às associações reconhecidas pelo selo Jeunesse et Éducation Populaire [Juventude e Educação Popular], nem mesmo aos movimentos que se referem explicitamente a essa denominação. Tais particularidades ainda aumentam a complexidade do que existe hoje sob a noção de educação popular: essa "nebulosa no meio de um mundo associativo de extrema diversidade" (PANTCHENKO, 2000, p. 6). Trata-se de um conjunto muito heterogêneo, embora alguns valores comuns sejam mobilizados de modo constante e sirvam para a construção e manutenção de uma identidade unívoca forjada pela forte herança histórica. Assim, apesar desses valores federativos, a educação popular permanece heterogênea e recheada de conflitos, como afirma Poujol: "outro mito muito resistente, o mito do unanimismo, ao passo que a realidade militante é feita de oposições, conflitos e rivalidades às vezes sem solução" (POUJOL, 1980, p. 1). Também para Luc Carton:

A educação popular é fruto de uma pluralidade de ascendências, de descendências e de pertenças. Essa pluralidade, porém, não basta para

\footnotetext{
5 "É impossível saber o número exato, por falta de dados estatísticos completos a respeito do mundo associativo, que é movediço e muito diversificado. Além disso, ao serem criadas, as associações registram-se na devida repartição, mas não são obrigadas a assinalar o momento em que deixam de existir." www.vieassociative.gouv.fr/monde_asso_aujourdhui/ (página consultada em 15 de fevereiro de 2004).

${ }^{6}$ Credenciamento atribuído pelo Ministério da Juventude, da Educação Nacional e da Pesquisa.
} 
formar um conjunto coerente; serve talvez para enunciar o referente democrático, inerente ao método da educação popular, mas é ainda insuficiente para defini-la (CARTON, 1998a.).

Com sua história longa e plural, a educação popular não forma portanto um conjunto homogêneo, mas é marcada por uma filosofia comum que busca a emancipação social, cultural e política do povo. Mas de que povo se trata? A quem se dirige a educação popular? Para quem se mobilizam seus atores? O que está por trás do termo "popular" na educação popular?

\section{Educação popular: para quem?}

Historicamente, os movimentos de educação popular dirigiam-se aos operários, mas de modo individual e numa tentativa de aproximação das classes (POUJOL, 1980, p. 21).

De modo geral, tentando remediar os desequilíbrios, ela se dirige às vítimas de desigualdades sociais e culturais; hoje, jovens e adultos são eventuais públicos para a educação popular que afirma um desejo de não-discriminação. De fato, ela pretende ser uma educação para todos (CACÉRÈS, 1964, p. 170). O termo popular afirma "a vontade de dirigir-se a todas as camadas da população, com uma atenção especial para aquelas que estão despossuídas de bens, saberes ou poderes legitimados" (DEGÉE, 2003).

Segundo Maurel (2000, p. 56), existem três conceitos de povo e, por conseguinte, três princípios de ação que dele decorrem respectivamente; ora, esses três conceitos são contraditórios e até conflitantes. Na concepção política de povo vinda do século XVIII, trata-se do povo chamado a manifestar-se pelo voto, ou seja, de um conjunto de cidadãos soberanos constitutivos da vontade geral transcendendo a diversidade dos indivíduos (legitimidade do universal, Lei Condorcet etc.). A esse conceito, acrescenta-se o conceito social de povo, no qual este último representa a fração que sofre, reunindo pessoas e grupos sociais que não participam da vontade geral. Por último, o conceito antropológico de povo entendido como uma comunidade regida pelo fato de partilhar uma identidade. Ora, a educação popular situa seu campo de ação no cruzamento desses três conceitos. Nesse contexto, "as perguntas feitas a quem trabalha com a educação popular e com a cultura são as seguintes: como estabelecer um acordo com valores e saberes que devem construir-se a partir de compromissos tão diversos e contraditórios?" (MAUREL, 2000, p. 61). São portanto diversificados os públicos nos quais a educação popular pretende agir.

Tais elementos permitem abordar agora a questão do encontro entre a educação popular e a sociedade da informação. Trata-se de compreender por que certos atores da educação popular se referem à sociedade da informação, em seus discursos e, às vezes, na ligação com a prática. Os elementos abordados até aqui permitem examinar a atual situação do campo da educação popular; cabe agora esmiuçar esses elementos para entender no que há encontro, quais os motivos e o sentido que ela assume diante das evoluções pelas quais está passando.

\section{Educação popular e sociedade chamada da informação: um encontro esperado}


Apesar da diversidade de filiações ideológicas, tanto de uma como da outra parte, o encontro entre os movimentos de educação popular e a sociedade da informação pode ser explicado por certas conexões e por um contexto favorável.

\section{Filiações seguras}

Mesmo que a adoção do conceito de sociedade da informação pelos atores do movimento de educação popular possa surpreender, cabe lembrar que essa aproximação procede de uma forte conexão entre as preocupações fundamentais da educação popular e as novas formas de exclusão e promessas engendradas pela sociedade da informação. Certos setores da educação popular são muito receptivos aos objetivos e à temática da sociedade da informação. Mas, nisso, guardam fidelidade a uma tradição de inovação na utilização dos meios de comunicação de massa. Essa tradição remonta aliás ao início do século XIX: "As associações de educação popular de meados do século passado acompanharam uma forma de reflexão popular adaptada às imposições tecnológicas (ver o caso dos cineclubes) [...] (LE CROSNIER, 2002). O projeto de apropriação dos instrumentos aparece como elemento constante no campo da educação popular. Assim como as discussões acerca da sociedade da informação tratam de antigas problemáticas recorrentes e concomitantes às inovações técnicas.

Percebida por seus militantes como instrumento de transformação social, a educação popular coloca a cultura no centro de seu processo, pois ela permite atuar sobre a representação da comunidade e, assim, nela agir. Nesse sentido, o domínio dos instrumentos específicos de uma sociedade marcada pelo aumento dos fluxos tecnológicos e informacionais representa uma das vertentes do trabalho sobre o ambiente e sobre a representação. Além disso, numa perspectiva de democratização do saber, a educação popular sempre procurou integrar os suportes e instrumentos desse saber - imprensa, livro, cinema, televisão e hoje os computadores, redes informáticas, Internet etc. - ao seu trabalho educativo. Percebe-se que o trabalho da educação popular não se opõe, em sua essência, à utilização dos meios de comunicação de massa e das novas tecnologias da informação e da comunicação, se eles se integram num projeto de educação popular.

Fornecer, a todos, os meios de conhecer, compreender e agir na sociedade, para emanciparem-se e não lhe ficarem submissos: eis o objetivo que se propõem os atores da educação popular. Ora, as tecnologias da informação e da comunicação representam um instrumento que pode ir nesse sentido. Mas é preciso que elas estejam integradas num projeto de educação popular - é este o ponto considerado mais importante pela maioria dos atores da educação popular. Esse objetivo está claramente explicitado no Livro Branco da educação popular: "O desafio está em não ignorar este modo de comunicação, mas em apropriar-se dele [...] (LETERRIER, 2001, p. 55). Aparece também a necessidade de aceitar a inovação, de não ficar marginalizado nem excluído: "Já que a utilização dos instrumentos da sociedade da informação se torna prova de normalidade, a igualdade de chances e a acessibilidade do maior número de pessoas a esses instrumentos é um imperativo" (LETERRIER, 2001, p. 55). Para outros atores da educação popular, a sociedade da informação é sociedade de telas, e estas permitem aproveitar - e ao mesmo tempo ameaçam - as práticas da educação popular. Haveria algumas aproximações entre as telas da sociedade da informação e a educação popular como educação fora da escola. Como indica Jacques Demeulier, diretor geral dos Céméa: "As telas são [...] o compromisso ideal entre a cultura e o 
lazer. Encarnam todo o objetivo da educação popular: aprender fora da escola. [...] A luta para integrar as telas nos projetos populares ainda está diante de nós". (DEMEULIER, 2000).

Este quadro reúne alguns pontos de convergência:

\begin{tabular}{|c|c|c|c|c|c|}
\hline & $\begin{array}{c}\text { Desafios } \\
\text { sociais }\end{array}$ & $\begin{array}{c}\text { Forma } \\
\text { democrática }\end{array}$ & $\begin{array}{c}\text { Alcance e } \\
\text { materialidade }\end{array}$ & Prática & Contexto \\
\hline $\begin{array}{c}\text { Educação } \\
\text { popular }\end{array}$ & $\begin{array}{c}\text { Educação } \\
\text { para todos, } \\
\text { sem } \\
\text { discriminação } \\
\text {, promoção } \\
\text { individual e } \\
\text { coletiva }\end{array}$ & $\begin{array}{l}\text { Democratizaçã } \\
\text { o cultural, fazer } \\
\text { do cidadão um } \\
\text { ator }\end{array}$ & $\begin{array}{c}\text { Universalismo e } \\
\text { trabalho nas } \\
\text { margens }\end{array}$ & \begin{tabular}{|} 
Tradição de \\
utilização dos \\
meios de \\
comunicação de \\
massa, \\
tradicionalment \\
e não formal e \\
não institucional
\end{tabular} & $\begin{array}{l}\text { Nova fase de } \\
\text { ruptura, crise } \\
\text { de identidade }\end{array}$ \\
\hline $\begin{array}{c}\text { Sociedade } \\
\text { da } \\
\text { informaçã } \\
0\end{array}$ & $\begin{array}{l}\text { Acesso para } \\
\text { todos à } \\
\text { informação }\end{array}$ & $\begin{array}{c}\text { Democracia } \\
\text { participante } \\
\text { (discurso sobre } \\
\text { a democracia } \\
\text { eletrônica e a } \\
\text { interatividade) }\end{array}$ & $\begin{array}{l}\text { Globalização,qued } \\
\text { a das fronteiras, } \\
\text { redes, } \\
\text { desmaterialização }\end{array}$ & $\begin{array}{l}\text { Foco sobre os } \\
\text { meios de } \\
\text { comunicação de } \\
\text { massa e os TIC, } \\
\text { mediação } \\
\text { técnica }\end{array}$ & $\begin{array}{c}\text { Estabilização } \\
\text { dos discursos } \\
\text { programático } \\
\mathrm{s}\end{array}$ \\
\hline
\end{tabular}

A apresentação dessas filiações e pontos de convergência esclarece quais as razões que levam à aproximação entre educação popular e sociedade da informação. Algumas particularidades deste modelo de sociedade inserem-se, em parte, na área de ação e nos modos de proceder dos atores da educação popular. Daí decorre a vontade que têm de explorar, a seu modo, o potencial do projeto de sociedade da informação. De fato, como pode a educação popular ignorar as possibilidades trazidas por esse modelo? Assim, a democratização é reivindicada pelos promotores e pelos poderes públicos para legitimar as políticas adotadas, enquanto ela é a finalidade primordial da educação popular, a razão primeira do recurso à técnica. A temática do acesso oferecido ao maior número de pessoas serve os interesses dos atores da educação popular, mas também é central no discurso dominante a respeito da sociedade da informação. Ao acesso, acrescenta-se a temática ligada à capacidade que cada um tem de produzir mensagens, de poder agir (desafio para a educação popular e argumento dos promotores da sociedade da informação). De fato, essa problemática dá outro alcance ao problema; ela procura saber se os dispositivos específicos da sociedade da informação facilitam o acesso ao espaço público ou se apenas dão a ilusão de proceder nesse sentido. Desse modo, o tema da luta contra a fratura numérica cristaliza, a nosso ver, toda a complexidade da relação entre educação popular e sociedade da informação.

2. Uma conjuntura propícia: a crise do simbólico 
Mas hoje os encantamentos com a implantação da sociedade da informação tendem a se cristalizar, enquanto a educação popular se encontra, de novo, numa fase de redefinição. Tanto os atores da educação popular quanto os promotores da sociedade da informação passam por uma fase crítica. Tal conjuntura é mais uma razão para essa aproximação. A educação popular procura redefinir seu papel na sociedade, ao passo que os discursos sobre a sociedade da informação se estabilizam (ou até se dissipam em proveito de outros conceitos). Por isso os promotores da sociedade da informação têm a necessidade de instaurar dispositivos, lugares, conteúdos e conexões para que se desenvolvam usos. Assim, um pode servir ao outro. Através dessa aproximação, os promotores da sociedade de informação podem usufruir da legitimidade e da credibilidade sociais da educação popular (legitimação social), e os atores da educação popular, do potencial de reconhecimento e de visibilidade específico da sociedade da informação. A educação popular pode ser uma etapa e um mediador para desenvolver as redes numéricas, ao passo que essas redes interrogam os atores da educação popular que se acham numa fase de ruptura e de redefinição, como se vê na oferta pública de reflexão sobre o futuro da educação popular (LEPAGE, 2001). Parece também que a crise de sentido experimentada pelos atores da educação popular constitui uma das razões que explicam a sua vontade de referir-se ao conceito de sociedade da informação.

\section{O poder da referência e a questão da adesão}

Mas convém distinguir dois níveis de abordagem na problemática aqui estudada: o primeiro situa-se na análise de uma tradição de inovação e de utilização dos objetos técnicos (como já apresentado anteriormente), o segundo situa-se na análise da referência a um conceito como o de sociedade da informação. Se, num primeiro momento de nossa pesquisa, foi uma surpresa encontrar essa referência no âmbito da educação popular, logo compreendemos que tal referência se situava numa certa continuidade e numa lógica compreensível sob o aspecto histórico. Mesmo assim, se a utilização, a apropriação e o uso dos objetos técnicos é uma coisa, a referência a um conceito tão marcado como o de sociedade da informação logo apresenta questões de outra natureza. Mesmo quando o encontro é discursivo, vê-se que essa referência ainda anterior às práticas já acarreta questões consideráveis. Por isso, nosso objetivo é avaliar essas questões e ver no que a mera referência (antes mesmo de falar de práticas) já modifica o jogo de poder. O que leva a situar um primeiro desafio no nível da produção de estratégias discursivas, e a considerar que elas são mais que o reflexo dos desafios existentes: são o próprio lugar de elaboração do político e, portanto, do confronto. Porque, se a educação popular é próxima de um campo de práticas, não deixa de ser uma ideologia sustentada por um conjunto de discursos. Além disso, a educação popular recobre uma área muito heterogênea e, portanto, embora haja referência ao conceito de sociedade da informação, este último não será apreendido de modo uniforme por todos os atores dessa área.

É possível afirmar que a sociedade da informação traz novos desafios aos atores da educação popular: ela renova as práticas tradicionais derrubando as fronteiras existentes entre elas (POULY, 2001). Dividida entre a fidelidade aos valores da educação popular muito apoiados na história e a exploração de novas vias ligadas às tecnologias de informação e de comunicação, a educação popular tende a examinar melhor o que a sociedade da informação transforma, amplia, destrói ou renova. No caso, a adesão não seria total nem incondicional, mas o encontro é bem real e talvez seja, segundo os atores da educação popular, a garantia de uma possível 
democratização da sociedade da informação. Como afirma Jean-Marc Roirant": "Almejamos um terceiro tipo de encontro entre a sociedade da informação e a educação popular. Será uma das chaves da natureza, democrática ou não, da sociedade da informação" (ROIRANT, 1997).

História complexa, realidade heterogênea, diversidade de públicos e de domínios de intervenção, a educação popular representa um campo cujas fronteiras estão em contínua construçãodesconstrução. Se certas filiações mostram que a temática da sociedade da informação procede de fortes ascendentes nos movimentos da educação popular, veremos que a crise de sentido que estes movimentos conhecem também revela as contradições existentes nessa aproximação.

\section{Contradições e desafios no encontro com a sociedade da informação}

Mas a que corresponde exatamente esse encontro? Como a referência à sociedade da informação questiona a educação popular e a transforma? Quais são os valores que vão se construir ou desconstruir? Quais são os desafios para delimitar fronteiras no campo da educação popular? Porque é, de fato, a identidade da educação popular que é questionada. Por trás das filiações comuns entre as problemáticas e valores próprios da educação popular e os argumentos da sociedade de informação, continuam presentes pontos de divergência que ressaltam os desafios dessa aproximação. Que conflitos se destacam pela aproximação dos atores da educação popular com a temática da sociedade da informação?

\section{Consenso só na aparência}

Ao analisar com mais pormenores o mal-estar da educação popular, veremos como a referência à sociedade da informação se agrega a problemáticas conflituosas já existentes, e como essa referência faz confrontarem-se as contradições existentes no encontro entre educação popular e sociedade da informação.

\section{Pacificação social e conflitualidade social}

Há muito que os poderes tentam instrumentalizar o meio associativo. Ora, o campo da educação popular constitui o lugar simbólico de uma possível tensão entre os interesses provenientes do topo e os que emanam da base. Logo, é essencial que as associações de educação popular se mantenham dentro da ordem social, embora capazes de protestar quando necessário, já que, por essência, elas completam ou preenchem o campo institucional.

\footnotetext{
${ }^{7}$ Secretário geral da Liga do Ensino na França.
} 
Por outro lado, se a sociedade da informação for considerada como um projeto gerador da paz social, aqui também a educação popular se distingue. A vontade de "refundar" a educação popular passa por uma reabilitação do conflito, pois

tudo acontece como se a cultura política dominante continuasse a se apoiar na redução ou evicção dos conflitos e procurasse obstinadamente o consenso. Mas o contexto atual estimula a tentativa de redefinir as discussões e os conflitos sociais. (CARTON, 1998a.).

A conflitualidade permanece um dos princípios de construção cidadã que a educação popular muito preza. Assim, "A educação popular renovada deve manter sua parte de conflitualidade e de autonomia para favorecer uma política do Sujeito, a emancipação e a promoção social de atores desejosos de se engajar politicamente no mundo". (BOUCHER, 2001).

Historicamente, porém, a educação popular também foi entendida como meio de pacificação social: "A educação popular encontra sua origem no século XIX, época de transformações sociais e políticas. Aos olhos de muitos responsáveis, educar o povo parece muitas vezes o modo de lutar contra as dissidências operárias e de chegar à pacificação social" (BARBIER, 2004).

Para muitos, a educação popular tornou-se a muleta de um sistema que produz desigualdades e precariedade, e isso faz duvidar de seu papel de contestadora do sistema. Não pode haver educação popular sem contestação da realidade, e nem até sem subversão: "o que desde sempre conferiu legitimidade à educação popular e ao movimento associativo: sua faculdade de subverter (BERTIN, 2000, p. 42). É a respeito desse papel que os militantes se indagam: em que ponto estamos, neste momento em que inúmeros projetos propostos pela educação popular foram pouco a pouco institucionalizados e integrados a dispositivos ligados às políticas públicas (no caso que nos concerne, cabe indagar, por exemplo, sobre os espaços públicos digitais.

Esses dispositivos tornam-se imposições e fazem do campo da educação popular um espaço de apoio, de reparação social, e não de questionamento; funcionam como uma série de ações que sustentam o sistema em vez de questioná-lo. Assim, "[...] as associações de educação popular tornaram-se empresas de conserto das brechas no tecido e na coesão social, empresas de atenuação dos efeitos negativos e nocivos do capitalismo" (LE COURRIER FERC, 2002, p.3). A dicotomia emancipação-integração faz parte da história desse movimento: "[...] a educação popular vai parecer mais integradora que emancipadora [...].Durante toda a história da educação popular, o par emancipação-integração será uma de suas maiores ambigüidades" (BARBIER, 2004).

À tensão gerada por essa dicotomia, junta-se a falta de reconhecimento do legado da educação popular: "Cada vez que nossas idéias ganharam terreno, houve como efeito perverso para nós [...] o não-reconhecimento das origens de dispositivos como o $\mathrm{CEL}^{8}$, o CTL, a VAE etc." (PECKRE, 2004, p. 3-4).

Os movimentos de educação popular vêem-se, portanto, cercados por conflitos: entre demanda social e encomendas públicas, entre trabalho informal e institucionalização, entre lógica militante e lógica gestora (ROUSSEAU, 2001). Em tal contexto, resta saber se o projeto de sociedade da informação está no mesmo sentido da demanda social, do trabalho nas margens e do trabalho militante, ou, ao contrário, se ele intensifica as lógicas de integração, de encomenda pública, de institucionalização e de gestão.

${ }^{8}$ CEL: Contrato educativo local; CTL: Convenção do tempo livre; VAE: Validação do adquirido pela experiência. 


\section{Projeto técnico / projeto social}

Além disso, a educação popular se fundamenta na existência de um projeto social específico, inserido num verdadeiro "húmus cultural e social"'. Em geral, o meio associativo tem a particularidade de basear-se numa dinâmica social forte, que atualmente parece contar com o desenvolvimento das redes numéricas. O uso dessas redes, nesse meio específico, é marcado por uma dimensão sobretudo social cujo fio condutor é a ampliação das práticas sociais preexistentes. Todos os atores da educação popular que se referem explicitamente à sociedade da informação concordam neste ponto: a primazia do projeto social de educação popular em relação à técnica. Por isso, os atores da educação popular procuram avaliar as potencialidades e também os riscos ligados ao desenvolvimento da sociedade chamada da informação, afirmando a necessidade de assimilar o que é possível a fim de colocá-lo a serviço das finalidades sociais e educativas da educação popular. Como afirma Christian Gautellier ${ }^{10}$ :

[...] Esses desafios e suas imposições não são uma novidade, são bem próximos de outros setores de conteúdos, como os do audiovisual ou do cinema, há muitos anos bastante freqüentados pela educação popular [...]. As fortes e reconhecidas potencialidades das novas tecnologias da informação e da comunicação são quase sempre o eco dos sonhos de educação e de cultura dos atores sociais. As realidades de seu desenvolvimento e as imposições do mercado no qual elas vivem requerem, no entanto, uma vigilância permanente, tanto mais porque os discursos "tecno-utopistas" são quase sempre a única referência. Um engajamento em novas práticas e a implicação dos atores bem além de seu status de consumidores, como produtores de sentido, permitirão que esses sonhos não sejam ilusões e que essas utopias possam concretizar-se em proveito do conjunto dos cidadãos. Na realidade, é esse o projeto sempre atual da educação popular (GAUTELLIER, 1998).

Logo, é na materialidade de um corpus social e de uma identidade forte que ocorre a aproximação com a sociedade da informação. Mas a sociedade da informação, tal como aparece nos promotores econômicos e institucionais, não se apóia num projeto social preexistente, mais parece substituí-lo. As vantagens econômicas potencialmente geradas por essas redes numéricas não estão na origem do desenvolvimento da sociedade chamada da informação; só recentemente a temática dos usos sociais se ampliou e foram concretamente destacados os usuários, os usos e os conteúdos.

\section{Linguagem e técnica: lugares de luta}

\footnotetext{
${ }^{9}$ Segundo a expressão utilizada pela associação Vecam, "Qual democracia na era informacional?" (VECAM, 2004)

${ }^{10}$ Diretor das publicações dos CÉMÉA (Centros de treinamento dos métodos de educação ativa).
} 
Os pontos de convergência evocados no item anterior representam também terrenos de luta, por serem argumentos consensuais irrefutáveis. Seria essa a manifestação de uma forma de violência simbólica como define Bourdieu: "A violência simbólica é a que se extorque das submissões que nem chegam a ser percebidas como tais, por se apoiarem em expectativas coletivas, crenças socialmente inculcadas"? (BOURDIEU, 1994, p. 188). Será que a evolução das terminologias que evocam essa nova sociedade (sociedade da informação, sociedade da comunicação, sociedade do saber, sociedade do conhecimento...); "Eis que chega a Sociedade da informação, a Sociedade da comunicação entre os seres humanos, a Sociedade do conhecimento e dos saberes compartilhados e, sobretudo, a Sociedade da solidariedade de todos os habitantes do nosso planeta" (SAMASSÉKOU, 2003) participa da mesma tendência? Parece indispensável estudar os deslizes semânticos e as pluralidades de sentido que essas evoluções recobrem, semelhantes a uma verdadeira batalha semiótica.

Deduz-se que, apesar das filiações, elas não garantem o consenso das representações. Persistem, além disso, fortes contradições, como já foi dito. Alguns pontos de ruptura apresentados a seguir possibilitam ir no sentido de sua análise:

\begin{tabular}{|c|c|c|c|}
\hline & $\begin{array}{c}\text { Produção e } \\
\text { transmissão de saber }\end{array}$ & $\begin{array}{l}\text { Relações sociais, } \\
\text { vínculo social }\end{array}$ & $\begin{array}{l}\text { Poder, relação com o } \\
\text { político }\end{array}$ \\
\hline Educação popular & $\begin{array}{l}\text { Modelo de educação } \\
\text { complementar, } \\
\text { construção de saber a } \\
\text { partir da experiência e } \\
\text { do coletivo }\end{array}$ & $\begin{array}{c}\text { Trabalho de } \\
\text { proximidade, ação } \\
\text { coletiva, mediação } \\
\text { humana e } \\
\text { acompanhamento, } \\
\text { vínculo social pela } \\
\text { troca }\end{array}$ & $\begin{array}{l}\text { Tecido associativo, } \\
\text { contrapoder, corpo } \\
\text { intermediário }\end{array}$ \\
\hline $\begin{array}{c}\text { Sociedade } \\
\text { daInformação }\end{array}$ & $\begin{array}{l}\text { Desenvolvimento da } \\
\text { teleaprendizagem, } \\
\text { passagem do modelo } \\
\text { educativo entralizado } \\
\text { e transmissivo para } \\
\text { uma lógica de rede, } \\
\text { confusão informação } \\
\text { e saber }\end{array}$ & $\begin{array}{c}\text { Distanciamento, } \\
\text { mediatização, } \\
\text { individualização das } \\
\text { práticas, } \\
\text { desintermediação }\end{array}$ & $\begin{array}{l}\text { Origem libertária, } \\
\text { mas retomada pelo } \\
\text { discurso liberal, } \\
\text { economismo, modelo } \\
\text { desenvolvido pelos } \\
\text { poderes públicos e } \\
\text { pelas instâncias } \\
\text { econômicas }\end{array}$ \\
\hline
\end{tabular}

Se os instrumentos tecnológicos pelos quais se desenvolve e se apresenta a sociedade da informação facilitam os procedimentos de controle, será que as associações de educação popular, ao adotar esses mesmos instrumentos, acabam se tornando auxiliares de um certo controle social e promovem um modelo consensual dessa sociedade? Ficam elas, assim, na posição de adotar o sistema de valores inerente a esse modelo, agregando seus discursos e suas práticas? Isso faz com que se examine o caráter performativo do objeto técnico, bem como o da influência do quadro simbólico aceito ou reivindicado no qual se inscrevem as práticas. 
De fato, além dos discursos, a técnica aparece como mestre-de-obras do processo de adesão a esse modelo de sociedade (pela implantação das redes, pela prescrição dos usos, pela propagação no cotidiano e na intimidade). Os discursos e os dispositivos são indissociáveis nesse processo de adesão. O modelo da sociedade da informação parece realizar-se por meio de um conjunto de dispositivos sociotécnicos que tendem a objetivar e formalizar as práticas. Estes dispositivos não produzem normas, modos de expressão, modos de ação, e até modos de ser?

Se esses dispositivos, no âmago da dinâmica de convergência, tendem a reduzir as margens de liberdade, a pré-inscrever as práticas sociais num esquema técnico, quais serão as margens de manobra, por trás das normas e dos protocolos assim definidos? Será possível confiar na particularidade e na ligação histórica desses movimentos, como garantia de sua singularidade e de sua margem de liberdade em relação ao modelo consensual da sociedade "da informação"? Esse modelo parece ser o lugar para o qual convergem interesses divergentes que surgem como que levados por uma mesma dinâmica. Diante dessas considerações, cabe a hipótese de que as tentativas de objetivação da sociedade da informação se caracterizem por lógicas conflituosas e por processos de negociação permanente entre os atores que a ela se dedicam.

\section{Os desafios para a educação popular: a identidade em questão}

O encontro com a temática da sociedade da informação, como já vimos, provoca indagações sobre os movimentos de educação popular. Trata-se agora de examinar os desafios desse encontro no âmbito interno. Ou seja, como as filiações, tensões e contradições evocadas anteriormente levam a um questionamento da própria identidade dos movimentos de educação popular.

1. Crise de sentido e dissonâncias

O mal-estar efetivo da educação popular tem origem sobretudo nas evoluções históricas e estruturais mais amplas que levam a um certo descompasso. É o que ocorre no que se refere ao público; a educação popular não conseguiu adaptar-se à evolução dele. Assim, se o objetivo era ajudar todos os homens sem exceção a sair "das alienações dos ambientes de trabalho, de estudo, de família, de bairro, de lazer, [...] a experiência mostrou que esse processo não se faz sem percalços: foram essencialmente as classes médias que aproveitaram as aberturas culturais". (DEGÉE, 2003). Inúmeros discursos evocam a desarticulação da educação popular, que se deve ao fato de "o sistema social e cultural no qual ela se constituiu ter passado por grandes mudanças. Os referentes do humanismo e do coletivo foram substituídos pelos das identidades e das diferenças" (BARBIER, 2004). As novas modalidades de intervenção social interrogam também a concepção histórica da educação popular que hoje estaria ultrapassada (DOUARD, 2000, p. 155). Ora, os instrumentos tecnológicos da sociedade chamada "da informação" também questionam essas evoluções (militantismo eletrônico, multiplicidade dos engajamentos e das filiações, mediatização das relações etc.). Eis porque a temática da sociedade da informação se situa na linha das evoluções estruturais que criam problemas para a educação popular. 
A educação popular enfrenta uma crise de sentido que é palpável na multiplicidade de definições que existem e na quantidade de discursos alusivos à necessidade de refundar a educação popular. De fato, há alguns anos, surgiu um vasto movimento de autocrítica nos meios da educação popular. Diante das derivas consensuais, alguns militantes da educação popular desejam "repolitizar" a educação popular. A construção de uma reflexão própria e específica sobre os desafios da sociedade da informação parece concorrer para um esclarecimento dos campos de ação e de reflexão da educação popular: significará isso que tal construção participa também da "repolitização"? Ou será sinal de uma despolitização, ou, em todo caso, a marca de uma certa normalização das práticas educativas e políticas específicas da educação popular?

\section{Da ação ao campo}

Para muitos militantes, o "trabalho de educação popular" se situa antes de tudo na ação; mais na prática que nos discursos porque "a educação popular não é discurso, senão vira ideologia"11. Nessa óptica, a educação popular sempre se situa na ação, da qual extrai sua legitimidade. Tratase porém, a nosso ver, de um campo que também se formou pelo discurso, pela constante reafirmação dos valores e das lógicas que reúnem os atores desse campo.

Para alguns, há discursos em demasia; " o tempo mítico da educação popular foi o tempo em que não se falava dela, isto é, o tempo em que a educação popular era a dimensão cultural da produção da ação coletiva" (CARTON apud LEPAGE, 2001, p. 36). Para outros, a educação popular teria caído no ativismo ${ }^{12}$. Reencontra-se a dialética da ação nas expectativas dos movimentos de educação popular em relação às novas tecnologias. Além do acesso à informação, é a capacidade de produzir mensagens, de ser ator e não consumidor, o que se procura através desses instrumentos.

Ora, a sociedade da informação, esse "paradigma dominante do período histórico atual", é invocada como um princípio sagrado "apto a justificar qualquer política", mas esse termo também se apóia numa verdadeira construção teórica (GARNHAN, 2000, p. 56). De modo mais geral, parece que os recentes desenvolvimentos provocados pela vontade de gerar essa sociedade são a ocasião para compreender a necessidade de formalizar as modalidades de ação da educação popular, de passar da ação à reflexão sobre essa ação. Assim, segundo Maurel (2000), trata-se de implantar uma verdadeira praxiologia para ajudar o meio da educação popular a se constituir como campo no sentido de Bourdieu.

[...] A melhor via para superar ou contornar a instrumentalização da educação popular e do trabalho da cultura é a sua instrumentação intelectual e prática. Por lhe faltarem instrumentos teóricos e práticos é que a educação popular e o trabalho da cultura se vêm envolvidos, com o apoio de discursos, em projetos e processos ditados por outros. [...] Trata-se de participar da emancipação tanto intelectual como política de

\footnotetext{
${ }^{11}$ Fórum Social Europeu 2003 - FSE - (anônimo), seminário "Reinventar a educação popular".

${ }^{12}$ Alexia Morvan, participante do FSE, seminário.
} 
campos de práticas que, a seu modo, fazem da emancipação dos

indivíduos seu projeto fundador e central (MAUREL, 2000, p. 25).

\section{Utopias, ideologias e identidade}

Se o modelo de sociedade decorre, em parte, de representações utópicas quando ele define uma forma ideal de sociedade a construir tanto quanto um processo de construção, ainda assim, por trás dessa forma ideal, várias ideologias são reivindicadas. O modelo dominante da sociedade da informação se baseia tanto sobre uma ideologia de mercado como sobre uma ideologia da comunicação, operando numa mesma dinâmica de abertura de fronteiras, de globalização, de mediatização generalizada. Mas a sociedade da informação também é habitada por um imaginário científico e libertário (FLICHY, 2001, p. 43-109). Sejam quais forem suas origens utópicas, o recurso ao modelo da sociedade da informação remete, hoje, a uma verdadeira ideologia política legitimante (FLICHY, 2001, p. 36) na qual se atiram também atores que não pertencem diretamente a esse processo e não respondem necessariamente aos esquemas esperados. Pois a ideologia e a utopia constituem duas funções complementares dentro da "imaginação social e cultural" (RICOEUR, 1997, p. 17). Surge então a questão da identidade porque, se a ideologia permite a reprodução das classes e das relações de dominação, ela também funda os processos de construção da identidade e faz parte integrante da "estrutura simbólica da vida social" (RICOEUR, 1997, p. 25). Se uma parte da ideologia é aceita, é porque ela confere identidade; funciona por reconhecimento.

A nosso ver, quando os atores da educação popular se referem à sociedade da informação, eles se inscrevem nesse longo processo de construção da identidade. Mesmo que para eles seja um processo arriscado, há nele um convite para refundar o movimento e ampliar seu campo de ação com alianças inéditas. Assim, ao mesmo tempo em que se traduz por experimentações e apropriações (nos discursos e nas práticas), a referência à sociedade da informação também acompanha tentativas de recomposição interna do campo. Ela é o meio, para a educação popular, de atualizar suas problemáticas em relação às novas problemáticas sociais, de reinvestir o espaço público e as questões comunicacionais. Além disso, dada a onipresença nas esferas sociais dos discursos sobre a sociedade da informação, os atores da educação popular, ao se apropriarem dela, têm a possibilidade de confrontar sua visão (ou suas visões, já que não se trata de uma visão homogênea) com as visões dominantes, e até de iniciar estratégias de alianças.

\section{Conclusão}

Os militantes da educação popular concedem um lugar preponderante à capacidade de fazer sentido, de dar sentido à ação, à vida em sociedade. Em seus discursos a respeito de seu engajamento com a sociedade da informação, vê-se em primeiro lugar a vontade de apoderar-se dos instrumentos tecnológicos a fim de integrá-los num processo de educação popular. Ora, trata-se dos objetivos propriamente sociais e culturais da sociedade da informação. Assim, considerando a grande quantidade de projetos implantados pelas instâncias públicas para desenvolver essa famosa sociedade da informação, projetos que são criticados por sua falta de base cultural e social, e de conteúdo, por sua visão tecnicista, é interessante indagar se os atores 
da educação popular têm capacidade para se apropriar de tudo que esse tipo de projetos rejeita. Destacando o sentido da ação, o projeto, as intenções sociais e educativas antes de mais nada, a comunidade da educação popular tem decerto um papel considerável a desempenhar no desenvolvimento de uma sociedade da informação que sirva aos grandes princípios emancipadores reclamados por esse meio. Mas, como vimos, o recurso ao conceito de sociedade da informação também permite legitimar a economização do mundo e a desregulação econômica. Dessas considerações, depreende-se que o modelo da sociedade da informação estaria apto a servir paralelamente a várias ideologias. Enfim, a aproximação entre a educação popular e outros movimentos sociais, bem como o crescente interesse pelas problemáticas da comunicação e da tecnologia sugerem possíveis reconfigurações no interior mesmo da comunidade da educação popular.

Intervêm, porém, igualmente (e de modo contraditório) as tradições culturais, o peso dos ideais históricos e as reservas de certos atores da educação popular em relação a meios industriais cujos critérios e valores são estranhos à sua filosofia emancipadora e não lucrativa. Em particular, a fraseologia universalista e a ideologia irenista que revestem os grandes relatos da democracia virtual e da formação ao longo da vida fornecem com facilidade argumentos a outras categorias de atores. Estes, aliás, não ocupam forçosamente uma posição dominante nas instituições da educação popular. Mas eles buscam nessa fraseologia e nessa ideologia como legitimar as estratégias de aliança que vão adotar. Assim explica-se a efervescência que acompanha, nos meios da educação popular, a popularização da referência à sociedade da informação.

\section{Referências}

BARBIER, René. Cours de licence em ligne sur le sens de l'éducation: Séquence 9. Régards sur 1'histoire de l'éducation populaire. Disponível em: <http://educ.univparis8.fr/LIC_MAIT/weblearn2002/tele/hist09.pdf> , Acesso em 3 mar 2004.

BERTIN, J. L'obligation de subversion. Politis, [S.1.], n. 29, p. 42. fév./mars 2000. Numero horssérie : Éducation populaire: le retour de l'utopie.

BOUCHER, M. L'éducation populaire, la «nouvelle question sociale» et son projet d'émancipation?. Paris: Université d'été 2001 de Peuple et Culture, 2001. Disponível em: <www.peuple-et-culture.org/article.php3?id_article=207>. Acesso em : 4 mar. 2004.

BOURDIEU, P. Questions de sociologie. Paris: Minuit, 1992.

.Raisons pratiques. Paris: Seuil, 1994.

CACÉRÈS, B. Histoire de l'éducation populaire. Paris : Éditions du Seuil, 1964.

CARTON, L. Culture et démocratie, l'enjeu de la démocratie culturelle. E-pop, Paris: Ministère de la Jeunesse et des Sports, 1995. Disponível em: <www.educpop.org/contrib/reference/carton_culture.html>. Acesso em: 25 abr. 2004.

Les défis de l'éducation populaire. In: RENCONTRES pour l'avenir de l'education populaire: le travail de la culture dans la transformation sociale et politique. Paris: Ministère de la Jeunesse et des Sports, 1999a. [Actes des Rencontres des 5-6 novembre 1998 à la Sorbonne, 
Paris, organisées par le Ministère de la Jeunesse et des Sports]. Disponível em:<www.educpop.org/contrib/actes/ouverture.html\#2>. Acesso em: 25 abr. 2004.

Repères pour une synthèse des rencontres pour l'avenir de l'éducation populaire. In: RENCONTRES pour l'avenir de l'education populaire: le travail de la culture dans la transformation sociale et politique. Paris: Ministère de la Jeunesse et des Sports, 1999b. [Actes des Rencontres des 5-6 novembre 1998 à la Sorbonne, Paris, organisées par le Ministère de la Jeunesse et des Sports]. Disponível em:<www.educpop.org/contrib/actes/carton_cloture.html $>$. Acesso em: 25 abr. 2004.

DEGÉE, J.-L. Qu'est-ce que l'éducation populaire? Rencontres Internationales de l'Éducation Populaire 2003. Disponível em:<www.peuple-et-culture.be/articles.php?lng=fr\&pg=83>. Acesso em: 28 abr. 2004.

DEMEULIER, J. Bienfaits et dérives des écrans comme média de la culture populaire. In : SERVICE JEUNESSE ÉDUCATION POPULAIRE DE LA VILLE DE STRASBOURG (Org.). Éducation populaire: nouvelles données? Strasbourg : [s.n.], 2000. Rapport du Colloque Quatrièmes Rencontres d'Éducation populaire.

DOUARD, O. L'éducation populaire ou le droit à l'intelligence politique. Pour, Paris: Group de Recherche pour l'Éducation et la Prospective, n. 165, p. 151-157, mars 2000.

FLICHY, P. L’imaginaire d'Internet. Paris: La Découverte, 2001.

FREIRE, P. La pédagogie des opprimés. Paris: Maspéro, 1974.

LE COURRIER FERC, nº 316, Mars 2002.

LETERRIER, Jean-Michel. Citoyens, chiché! Le livre blanc de l'éducation populaire. Paris: Les Éditions de l'Atelier: Les Éditions Ouvrières, 2001.

GARNHAM, N. La théorie de la société de l'information en tant qu'idéologie : une critique. Réseaux, Paris, v. 18, n. 101, p. 53-91, 2000.

GAUTELLIER, C. Au cœur de l'éducation populaire. Vers l'Éducation Nouvelle: multimédia, école et société, [S. 1.], n. 487, nov. 1998.

Sous les ordinateurs, la pédagogie. In: CRINON, J.; GAUTELLIER, C. (Dir.). Apprendre avec le multimédia et Internet. Paris: Retz, 2001. Disponível em: www.cemea.asso.fr/multimedia/livremultitexte2.html. Acesso em: 25 abr. 2004.

LE CROSNIER, H. Démocratie, lien social et création à l'ère des NTIC. Disponível em: <http://users.info.unicaen.fr/ herve/publications/2002/mantes/>. Acesso em: 12 mars 2004. Introdução ao colóquio Éducation Populaire et Transformation Sociale, Fédération Française des Maisons des Jeunes et de la Culture, Mantes-la-Jolie, 26-27 mars, 2002

PECKRE, Nadège. Notes. In: LÉGER, Jean-Luc (org.). Atelier-débat de l'après midi. Évreux, 25 septembre 2003. Disponível em:

<www.francas.asso.fr/Hub/Portail/FRANCAS_PUB.nsf/0/6D35CCE56C9209FCC1256DB4003 0C922/\$File/Synthese_atelier.pdf. Acesso em: 6 maio 2004 
LEPAGE, F. Le travail de la culture dans la transformation sociale: une offre publique de réflexion du Ministère de la Jeunesse et des Sports sur l'avenir de l'éducation populaire. Paris: Ministère de la Jeunesse et des Sports, 2001. Rapport d'étape.

MAUREL, C. Éducation populaire et travail de la culture: éléments d'une théorie de la praxis. Paris: L'Harmattan, 2000.

Le travail de la culture: de nouveaux languages pour de nouvelles pratiques. [S.1.]: Fédération Française des Maisons des Jeunes et de la Culture Méditerranée, 2003.

PANTCHENKO, D. Éducation populaire : combien de divisions? Politis, [S.1.], n. 29, p. 6-7, fév./mars 2000. Numéro hors-série - Éducation populaire: le retour de l'utopie.

POUJOL, G. Éducation populaire. In: DICTIONNAIRE encyclopédique de l'éducation de la formation. Paris: Nathan, 1994.

Éducation populaire: histoires et pouvoirs. Paris: Éd. Ouvrières, 1980.

Introduction. In: POUJOL, G.; ROMER, Madeleine. Dictionnaire biographique des militants: XIXe-XXe siècles: de l'éducation populaire à l'action culturelle. Paris : l'Harmattan, 1996. p. 3.

POULY, J. Webtrotteurs, éducation populaire et société de l'information. I3C, [S.1.], 24 oct. 2001. Disponível: 〈www.i3c-asso.org/article.php3?id_article=87>. Acesso em: 10 mar. 2004.

RICHEZ, J.-C. Prefácio. In: SERVICE JEUNESSE ÉDUCATION POPULAIRE DE LA VILLE DE STRASBOURG (Org.). Éducation populaire: nouvelles données?. Strasbourg: [s.n.], 2000. Rapport du Colloque Quatrièmes Rencontres d'Éducation populaire.

RICOEUR, P. L'idéologie et l'utopie. Paris: Éditions du Seuil, 1997.

ROIRANT, J-M. La ligue et la société de l'information. Idées en Mouvement, [S.1.], aoûtseptembre 1997.

ROUSSEAU, F. L'éducation populaire: entre commandes publiques et besoins sociaux: le projet associatif est en crise de sens. Revue Internationale de l'Èconomie Sociale, [S.1.], n. 279, 2001.

SAMASSÉKOU, Adama. Le Sommet Mondial sur la Société de l'Information: premier pas vers une veritable société de la connaissance et des savoirs partagés. In: WORLD LIBRARY AND INFORMATION CONGRESS: IFLA GENERAL CONFERENCE AND COUNCIL, 69., 2003, Berlin. Proceedings... 2003, Berlim. Disponível em: <http://www.ifla.org/IV/ifla69/papers/151f-Samassekou.pdf> . Acesso em: 20 fev 2004.

VECAM. Disponível em <http://www.vecam.org> . Acesso: em 20 fev 2004. 